\title{
Reactive Retinal Astrocytic Tumor (Focal Nodular Gliosis): Report of the Clinical Spectrum of 3 Cases
}

\author{
Arun D. Singh ${ }^{a}$ Hansell Soto $^{a}$ Claudine Bellerive $^{a}$ Charles V. Biscotti ${ }^{b}, c$ \\ ${ }^{\mathrm{a}}$ Department of Ophthalmic Oncology, Cole Eye Institute, and ${ }^{\mathrm{b}}$ Anatomic Pathology, Cleveland Clinic, \\ Cleveland, $\mathrm{OH}, \mathrm{USA} ;{ }^{\mathrm{C}}$ Department of General Ophthalmology, National Institute of Diabetes, Endocrinology and \\ Nutrition, Santo Domingo, Dominican Republic
}

\section{Established Facts}

- Histopathologic, immunohistochemical, and molecular findings indicate predominance of astrocytes rather than vascular components within the vasoproliferative tumor.

- Reactive retinal astrocytic tumor has been proposed as an alternate terminology to describe retinal vasoproliferative tumor.

\section{Novel Insights}

- Reactive retinal astrocytic tumor can be observed in response to a degenerative, inflammatory, or ischemic retinal insult.

- The nature of this gliotic tumor may become apparent after treatment.

\section{Keywords}

Reactive astrocytic tumor of the retina - Glial fibrillary acidic protein - Vasoproliferative tumor

\footnotetext{
Abstract

Purpose: To report 3 cases providing insight into clinical progression of reactive retinal astrocytic tumor. Methods: The clinical, imaging, and when available, the cytologic features of 3 cases of reactive retinal astrocytic tumor (focal nodular gliosis) were reviewed. Results: A 6-year-old fe-
}

male, a 49-year-old man, and a 39-year-old man each developed a white retinal mass associated with laser photocoagulation, lattice degeneration, and treatment of a presumed vascular tumor, respectively. All tumors were white, circumscribed retinal masses that tended to be associated with exudation and either initially or eventually minimal vascularity. Conclusion: Reactive retinal astrocytic tumor can be observed in response to a degenerative, inflammatory, or ischemic retinal insult. Such tumors may progress after therapeutic intervention.

(c) 2017 S. Karger AG, Basel

\section{KARGER}

E-Mail karger@karger.com

www.karger.com/oop $\begin{array}{ll}\text { (c) } 2017 \text { S. Karger AG, Basel } & \text { Arun D. Singh, MD } \\ & \text { Department of Ophthalmic Oncology }\end{array}$

Cole Eye Institute, Cleveland Clinic

2022 E 105th St, Cleveland, OH 44106 (USA)

E-Mail singha@ccf.org 


\section{Introduction}

Reactive retinal astrocytic tumors are characterized by a globular yellowish-pink mass, in the inferior retinal periphery, surrounded by lipid exudation with normal-caliber feeder vessels. Other associated features include exudative retinal detachment, retinal and vitreous hemorrhage, and epiretinal membranes, all of which can contribute to loss of vision [1].

Recently published studies on histopathologic, immunohistochemical, and molecular findings indicate predominance of astrocytes rather than vascular components within the tumor $[2,3]$. Hence, reactive retinal astrocytic tumor $[2,3]$ has been proposed as an alternate terminology to describe these retinal tumors rather than labelling them as a vasoproliferative tumor [4], presumed acquired hemangioma [5], and peripheral retinal angioma [6], angioma-like [7, 8], angiomatous mass [9], or peripheral nodular retinal telangiectasis [10].

We report 3 patients, each with a single retinal tumor with predominant gliotic appearance that could be best labelled as reactive retinal astrocytic tumor. The clinical features of these cases and fine needle aspiration biopsy (FNAB) in 1 case provide further insight into the clinical presentation and progression of reactive retinal astrocytic tumors.

\section{Case Reports}

\section{Case 1}

A 6-year-old female with a diagnosis of bilateral idiopathic retinal vasculitis that had been treated (Fig. 1a) with panretinal photocoagulation and systemic steroids and methotrexate. Initial fluorescein angiography shows anomalous retinal vessels and extensive areas of nonperfusion (Fig. 1b). She presented with a rapidly growing multilobulated white retinal tumor $(11.0 \times 7.5 \times 2.8 \mathrm{~mm})$ in her right eye and neovascular glaucoma in the left eye. The tumor was associated with lipid exudation and centered over the area of previous laser photocoagulation scar (Fig. 1c). FNAB revealed benign cells with abundant fibrillar cytoplasm consistent with glial cells (Fig. 1d). Treatment with multiple sessions of double freeze-thaw cryotherapy and intravitreal bevacizumab was undertaken. One year following completion of local therapy and discontinuation of systemic therapy (steroids and methotrexate), the visual acuity was 20/60 with regression of the tumor and resolution of lipid exudation.

\section{Case 2}

A 49-year-old man was referred because of a retinal mass that was detected on a routine eye examination. Past medical history was pertinent for controlled insulin-dependent diabetes. Examination revealed best corrected visual acuity of 20/20 OU $(-2.00+$ $0.50 \times 170 ;-3.00+0.50 \times 40)$. Anterior segment examination of both eyes and fundus examination of the right eye was unremarkable. In the left eye, a white retinal mass $(8.0 \times 5.0 \times 2.0 \mathrm{~mm})$ in vicinity of the lattice degeneration without associated exudation was observed (Fig. 2a). Fluorescein angiography revealed absence of prominent feeder or intrinsic vessels (Fig. 2b). On ultrasonography $B$ and A scan, the lesion was irregularly structured with high internal reflectivity. The lesion has remained stable under observation over 1.5 years.

Case 3

A 39-year-old man presented with a retinal hemorrhagic vascular mass involving the inferior periphery of the right eye $(8.0 \times$ $6.0 \times 2.4 \mathrm{~mm}$ ). The mass was associated with surrounding lipid exudation. A clinical diagnosis of vasoproliferative tumor of the retina was made (Fig. 3a). He was treated with episcleral brachytherapy without complications (iodine- 125 plaque, $12 \mathrm{~mm}$ size, 45 Gy delivered over $48 \mathrm{~h}$ ). Because of lack of response and onset of proliferative retinopathy, intravitreal bevacizumab was administered $(1.25 \mathrm{mg}$ in $0.05 \mathrm{~mL})$. Within 4 weeks, the tumor appeared totally avascular and gliotic (Fig. 3b).

\section{Discussion}

As the terminology suggests, retinal astrocytic tumors are believed to be reactive rather than low-grade proliferations as the cells within the tumors have bland nuclei, do not exhibit mitoses, and have low Ki-67 proliferative indices [2]. The tumors also lack BRAF-KIAA gene rearrangement and IDH1-R132H mutation, which are markers of an astrocytoma $[2,11]$. In the central nervous system, the process of reactive astrocytosis is believed to represent a form of homeostatic mechanism to insults such as trauma, ischemia, inflammation, and others [12] that helps isolate the affected region from the neighbouring tissues, thereby limiting the lesion size [13].

These tumors are also known to occur secondary to a variety of retinal insults such as inflammation (pars planitis), degenerative disorder (retintis pigmentosa), and trauma (retinal detachment surgery) $[4,14]$. Case 1 with a diagnosis of bilateral idiopathic retinal vasculitis had been treated with panretinal photocoagulation. She presented with a rapidly growing multilobulated white retinal tumor $(11.0 \times 7.5 \times 2.8 \mathrm{~mm})$ associated with lipid exudation that centered over the area of previous laser photocoagulation scar. FNAB revealed only glial cells. The vascularity within the tumor was not evident on fundoscopy and on fluorescein angiography. Moreover, there was only localized pinpoint hemorrhage after diagnostic FNAB that revealed only astrocytes. Case 2 of an incidentally detected white retinal mass $(8.0 \times 5.0 \times 2.0$ $\mathrm{mm}$ ) in the vicinity of lattice degeneration was without obvious retinal vascularity. In Case 3, a hemorrhagic ret- 

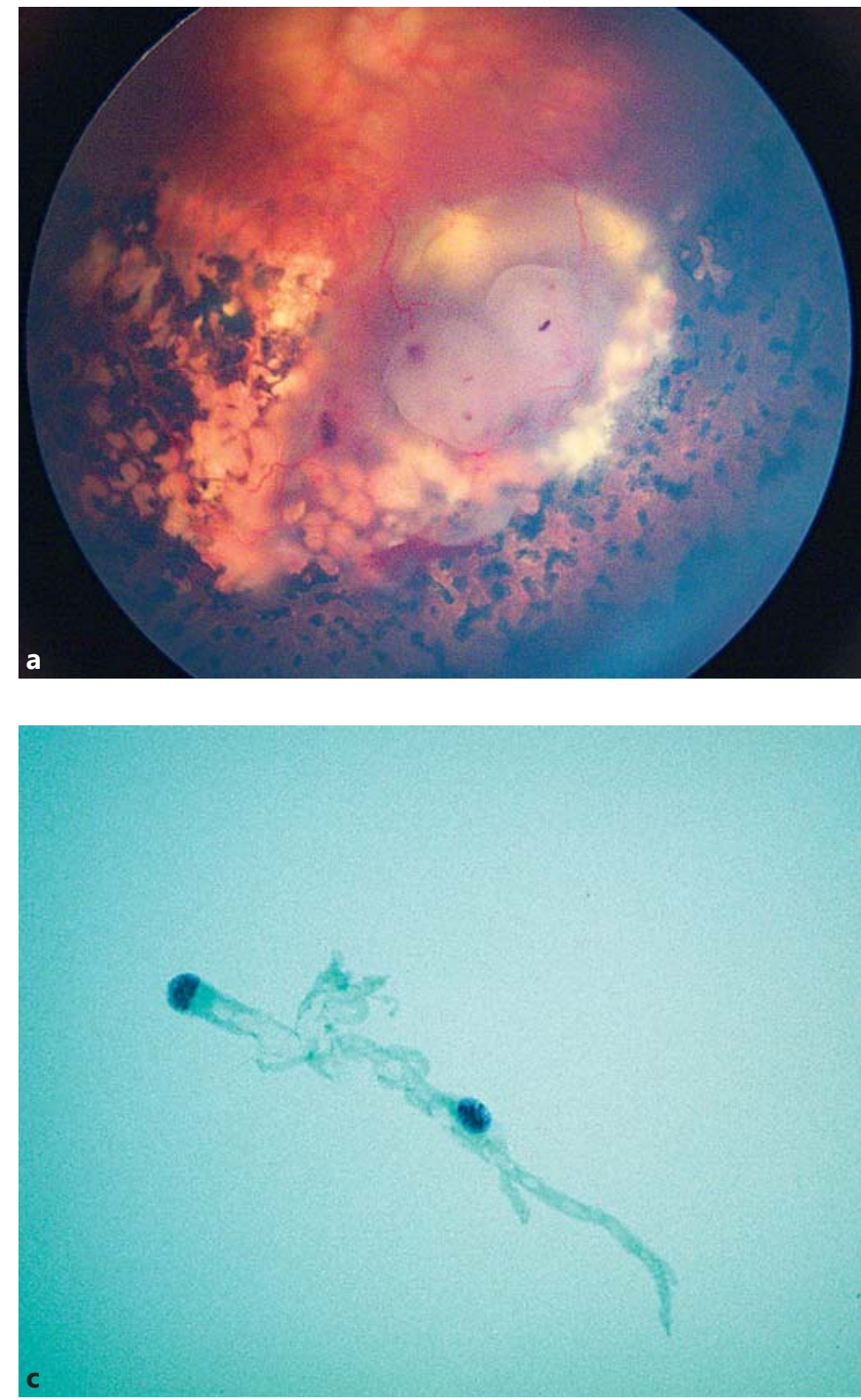

Fig. 1. Case 1. A solitary multilobulated, yellow white, circumscribed retinal tumor with fine intrinsic vessels located just outside the inferior arcades centered over the band retinal photocoagulation scars. The tumor was $11 \times 7.5 \mathrm{~mm}$ in basal dimensions with height of $2.8 \mathrm{~mm}$. Note surrounding rim of lipid exudation (a). Abundant fibrillary cytoplasm surrounds relatively uniform nuclei

inal vascular mass transformed into a white retinal mass after treatment with episcleral brachytherapy and intravitreal bevacizumab, interventions that target retinal vasculature inducing regression of existing or new vessels $[15,16]$. The findings in our patients are consistent with the reactive nature of this tumor, which may occur in a variety of settings. These tumors are slow growing, variably vascularized, and may eventually be classified as massive gliosis of the retina [17].

Reactive Retinal Astrocytic Tumor (Focal Nodular Gliosis)
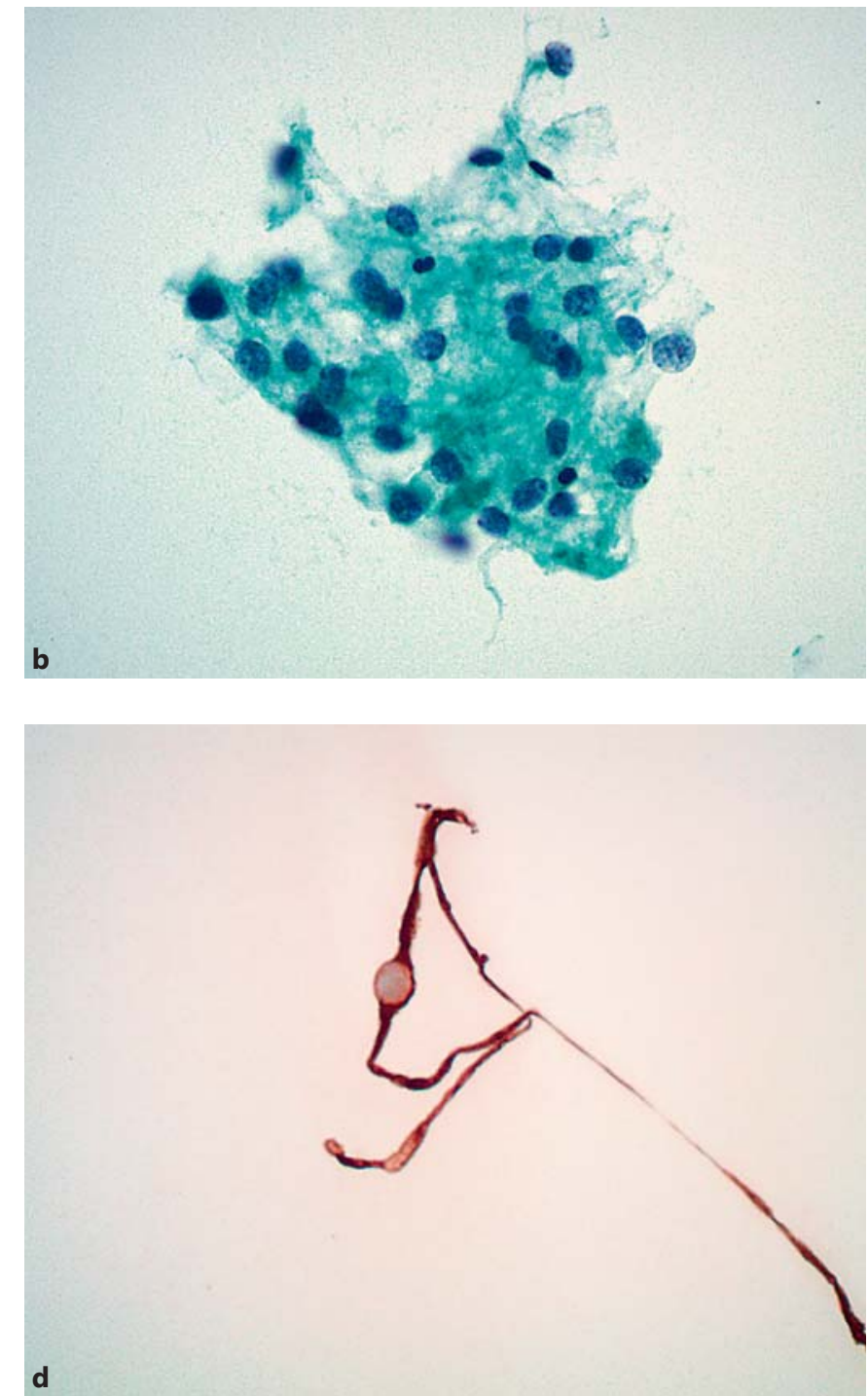

characteristic of reactive astrocytic glial cells (b, Papanicolaou stain, $\times 40)$. The astrocytic cells have elongated cytoplasmic processes (c, Papanicolaou stain, $\times 40$ ). The cytoplasmic processes stain strongly positive with the glial fibrillary acidic protein immunostain (d).

Related rare entities such as presumed solitary circumscribed retinal astrocytic proliferation [18-20] have clinical appearance of a white circumscribed, retinal lesion without prominent retinal vascularity in absence of associated subretinal fluid or hemorrhage and may be included within the spectrum of reactive retinal astrocytic tumors as well as acquired astrocytomas (not associated with tuberous sclerosis) that are composed of astrocytes lacking mitotic figures $[21,22]$.

Ocul Oncol Pathol 2017;3:235-239 

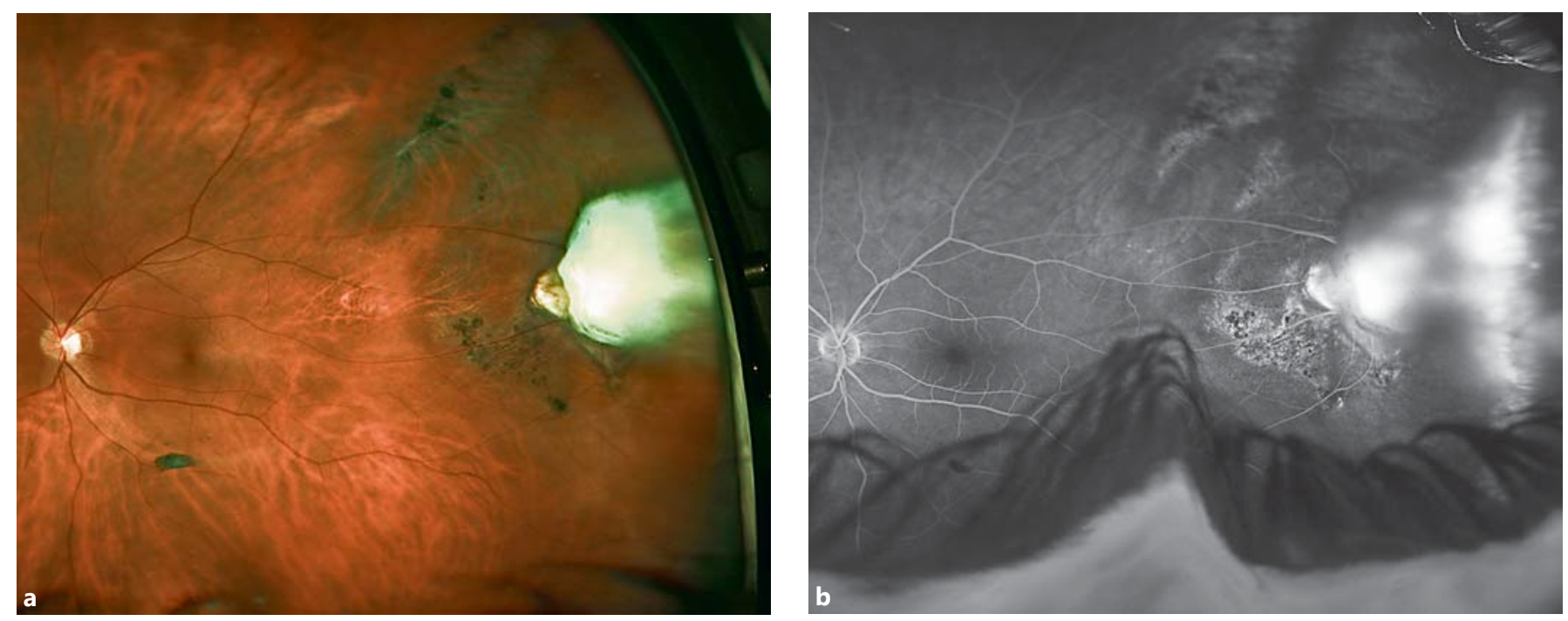

Fig. 2. Case 2. Incidentally detected white retinal mass $(8.0 \times 5.0 \times 2.0 \mathrm{~mm})$ in the vicinity of lattice degeneration without obvious retinal vascularity (a). Fluorescein angiography revealed absence of prominent feeder or intrinsic vessels (b).
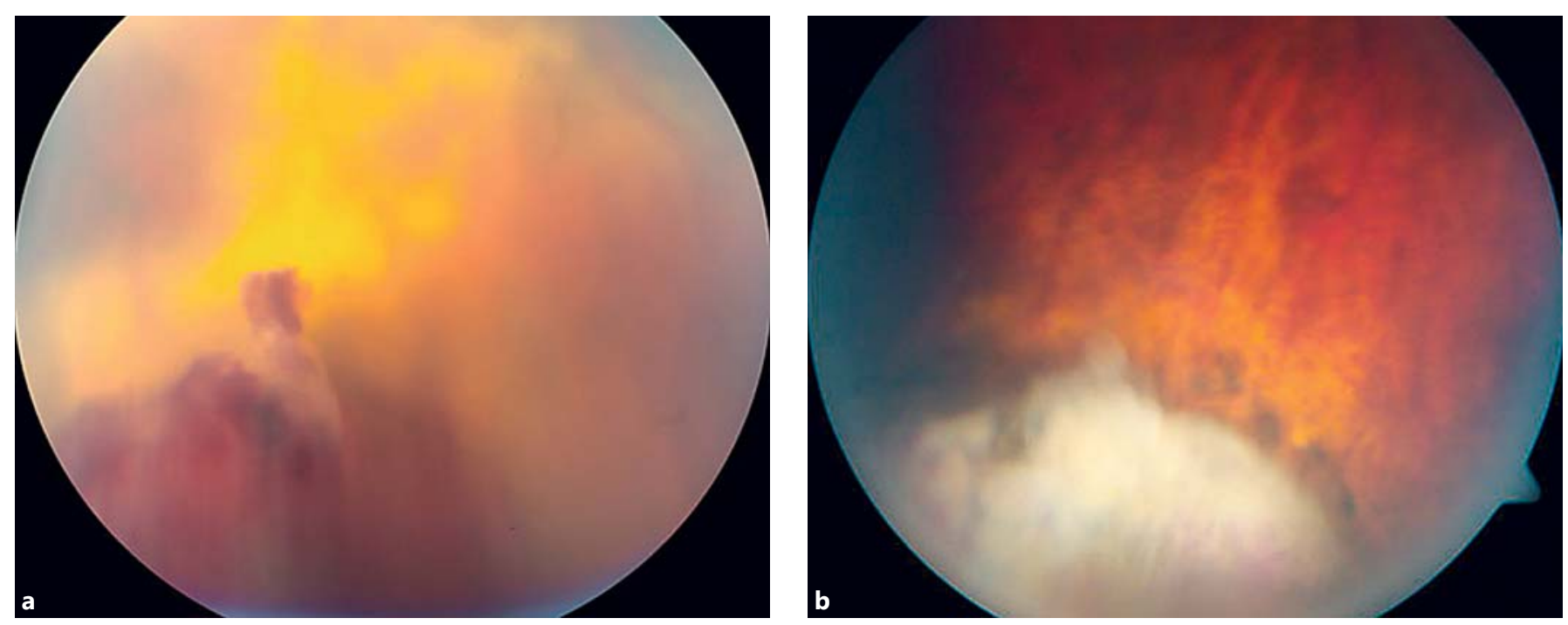

Fig. 3. Case 3. Fundus appearance of peripheral hemorrhagic tumor with prominent retinal lipid exudation (a). Following treatment with plaque radiation therapy ( $35 \mathrm{~Gy})$, there was onset of retinal neovascularization necessitating intravitreal injection of bevacizumab $(1.25 \mathrm{mg}$ in $0.05 \mathrm{~mL})$. Four weeks later, the tumor appeared totally avascular and gliotic (b). Reproduced with permission from Singh and Damato [1] (pp 17-34).

Taken together, clinical presentation of a white retinal tumor with minimal or absent vascularity (Case 1, Case 2) suggestive of astrocytic composition rather than a vascular tumor, presence of astrocytes on diagnostic FNAB (Case 2), location at the site of previous insult indicative of reactive etiology (Case 1, inflammation, ischemia, and laser scar; Case 2, lattice degeneration), and transforma- tion of vascularized tumor into a white retinal tumor following treatment with antiangiogenic therapy (Case 3) further support the proposed terminology of a reactive retinal astrocytic tumor. These tumors may be variably vascularized, although the primary process appears to be a reactive astrocytic proliferation. 


\section{Statement of Ethics}

The study complied with the guidelines for human studies and animal welfare regulations. The subject gave informed consent and the study protocol was approved by the institute's committee on human research.

\section{References}

1 Singh A, Damato B: Clinical Ophthalmic Oncology. Retinal Tumors, Second Edition. Berlin, Heidelberg: Springer, 2014.

2 Poole Perry LJ, Jakobiec FA, Zakka FR, et al: Reactive retinal astrocytic tumors (so-called vasoproliferative tumors): histopathologic, immunohistochemical, and genetic studies of four cases. Am J Ophthalmol 2013;155:593608.e1.

3 Jakobiec FA, Thanos A, Stagner AM, Grossniklaus HE, Proia AD: So-called massive retinal gliosis: a critical review and reappraisal. Surv Ophthalmol 2016;61:339-356.

4 Shields CL, Shields JA, Barrett J, De Potter P: Vasoproliferative tumors of the ocular fundus. Classification and clinical manifestations in 103 patients. Arch Ophthalmol 1995;113: 615-623.

5 Shields JA, Decker WL, Sanborn GE, Augsburger JJ, Goldberg RE: Presumed acquired retinal hemangiomas. Ophthalmology 1983; 90:1292-1300.

6 Henkind P, Morgan G: Peripheral retinal angioma with exudative retinopathy in adults (coats's lesion). Br J Ophthalmol 1966;50:211.

7 Barr CC, Rice TA, Michels RG: Angioma-like mass in a patient with retrolental fibroplasia. Am J Ophthalmol 1980;89:647-650.

\section{Disclosure Statement}

The authors have no conflicts of interest to declare.
8 Galinos SO, Smith TR, Brockhurst RJ: Angioma-like lesion in hemoglobin sickle cell disease. Ann Ophthalmol 1979;11:1549-1552.

9 Gottlieb F, Fammartino JJ, Stratford TP, Brockhurst RJ: Retinal angiomatous mass. A complication of retinal detachment surgery. Retina 1984;4:152-157.

10 Baines PS, Hiscott PS, McLeod D: Posterior non-vascularized proliferative extraretinopathy and peripheral nodular retinal telangiectasis. Trans Ophthalmol Soc UK 1982;102: 487-491.

11 Schindler G, Capper D, Meyer J, et al: Analysis of BRAF V600E mutation in 1,320 nervous system tumors reveals high mutation frequencies in pleomorphic xanthoastrocytoma, ganglioglioma and extra-cerebellar pilocytic astrocytoma. Acta Neuropathol 2011;121: 397-405.

12 Pekny M, Nilsson M: Astrocyte activation and reactive gliosis. Glia 2005;50:427-434.

13 Pekny M, Wilhelmsson U, Pekna M: The dual role of astrocyte activation and reactive gliosis. Neurosci Lett 2014;565:30-38.

14 Shields CL, Kaliki S, Al-Dahmash S, et al: Retinal vasoproliferative tumors: comparative clinical features of primary vs secondary tumors in 334 cases. JAMA Ophthalmol 2013; 131:328-334

15 Archer DB, Gardiner TA: Ionizing radiation and the retina. Curr Opin Ophthalmol 1994; 5:59-65.
16 Ferrara N, Davis-Smyth T: The biology of vascular endothelial growth factor. Endocr Rev 1997; 18:4-25.

17 Hudson LE, Mendoza PR, Yan J, Grossniklaus HE: Reactive retinal astrocytic tumor (focal nodular gliosis): a case report. Ocul Oncol Pathol 2017;3:1-7.

18 Shields JA, Bianciotto CG, Kivela T, Shields CL: Presumed solitary circumscribed retinal astrocytic proliferation: the 2010 Jonathan W. Wirtschafter Lecture. Arch Ophthalmol 2011; 129:1189-1194.

19 Schwartz SG, Harbour JW: Spectral-domain optical coherence tomography of presumed solitary circumscribed retinal astrocytic proliferation versus astrocytic hamartoma. Ophthalmic Surg Lasers Imaging Retina 2015;46: 586-588.

20 Asensio-Sanchez VM, Diaz-Cabanas L: Presumed solitary circumscribed retinal astrocytic proliferation. Arch Soc Esp Oftalmol 2016, DOI: 10.1016/j.oftal.2016.05.013.

21 Shields CL, Shields JA, Eagle RC Jr, Cangemi F: Progressive enlargement of acquired retinal astrocytoma in 2 cases. Ophthalmology 2004; 111:363-368.

22 Cohen VM, Shields CL, Furuta M, Shields JA: Vitreous seeding from retinal astrocytoma in three cases. Retina 2008;28:884-888. 